\title{
Arbor
}

\section{La ingeniería militar ilustrada y la frontera de Castilla}

Fernando R. de la Flor

Arbor CLXXIII, 683-684 (Noviembre-Diciembre 2002), 553-583 pp.

La defensa propia es la fortificación; en ella goza de sus bienes la paz, y de su socorro la guerra; se vive con quietud, y se teme menos a la hostilidad, porque guarda el sueño a los que abriga. Ella aumenta los comercios, porque guarda los muros a la habitación, que son sus puertas.Bárbaros son los hombres que peregrinan por el campo y por el monte con las armas; la fortificación los pone en compañía civil

Vicente Mut, Tratado de fortificación

La frontera que discurre entre Portugal y los territorios de los antiguos reinos de Castilla La Vieja y de León; el borde o zona liminar entre soberanías bruscamente separadas hacia 1640; lo que propiamente se conoció de manera local como la "Raya», se convierte a lo largo del siglo XVIII en un «laboratorio» de experimentación militar, y en una zona a redefinir estratégicamente en la política general que tiende al establecimiento de una defensa de las fronteras peninsulares, de antiguo amenazadas. Es en este marco, donde las obras constructivas de un poderoso núcleo defensivo, el conocido como Fuerte de la Concepción, van a alcanzar una importancia manifiesta, llegando a constituirse, en lo que a la provincia de Salamanca afecta, en la más significativa acción constructiva de un Estado que avanza hacia la Ilustración racionalizando sus campos de actuación, entre ellos marcadamente el militar. Este Fuerte de la Concepción, lejos de situarse en la exclusiva órbita de la arqueología militar o de constituir una pieza curiosa de los estudios locales es, en realidad, un emblema en 
el que se sustantiva el complejo juego de relaciones hispano-portuguesas, a partir de la fractura situada a la altura de la mitad del siglo XVII. $\mathrm{Su}$ posición singular desde todos los órdenes y puntos de vista, no sólo estratégicos, sino también de logística general del territorio, y hasta, me atrevería a decir, ideológicos - pues resume y condensa en su estructura poliorcética la estabilización espacial que persigue la Ilustración-, lo convierte precisamente en el objeto ideal del estudio de un dominio geofísico donde se asientan conflictiva y dialécticamente dos culturas.

\section{El cuadro de partida}

Es durante un período de paz, inusual en el reinado de Felipe V, enmarcado por las firmas de los dos primeros Pactos de Familia con Francia $(1733 ; 1743)$, cuando la posición de $L a$ Concepción se revela de nuevo como importante para cerrar el dispositivo de defensa peninsular, que es una de las empresas señaladas en la política del ministro de Felipe V, José Patiño.

La cobertura de la fachada mediterránea, objetivo prioritario para el ministro de Felipe V, quedaba asegurada desde la toma de Orán (1732) y el reconocimiento del futuro Carlos III como rey de Sicilia y Nápoles. Desde un punto de vista estratégico, la potenciación que recibe en estas fechas la base naval de Cartagena completó también el conjunto de disposiciones que aseguraban, en su versión mediterránea, la política internacional española ${ }^{1}$.

Es en ese momento, que podemos situar en torno a 1735, cuando toda la zona de la Frontera de Castilla adquiere una súbita importancia, al ser la misma paso tradicional de los ejércitos portugueses y de sus aliados ingleses.

Así, el Fuerte de la Concepción aparece vinculado doblemente a los acontecimientos de la política internacional del momento y de la estrategia de Patiño (que hace una visita personal al territorio) ${ }^{2}$, mantenida en los años que van de 1728 a 1740, y tendente a reordenar las relaciones con las dos potencias del bloque de Hannover (Inglaterra y Francia).

En concreto, la reconstrucción del Fuerte de la Concepción, en la que de alguna manera cristaliza la preocupación por la situación de indefensión en toda la Frontera de Castilla, es producto de un empeño personal de José Patiño, quien durante cinco años lucha por mantener la idea de esa reconstrucción, frente a todo tipo de dificultades. Entre 
estas últimas se pueden señalar, en primer lugar, las derivadas de la situación económica; pero también incidirán consideraciones de índole estratégica, al persistir en el ánimo de muchos de los expertos de la época las dudas sobre la conveniencia de fortificar una plaza tan adelantada.

Es tan cierta esta vinculación entre el ministro, de un lado, y, de otro, la fortificación de La Concepción, que ésta última sufrirá la primera de las interrupciones de obras que van a afectarla a lo largo del siglo XVIII, en la fecha de 1740, coincidiendo con la desaparición de Patiño del escenario de la política interior española.

Es antes, en 1735, a partir, probablemente, de la visita de Patiño al territorio de Frontera entre Portugal y España, cuando surge la idea de reconstruir el viejo fuerte demolido y potenciar, con una serie de medidas, sustancialmente referidas a intervenciones de ingeniería militar en obras ya existentes, la Frontera ${ }^{3}$.

La decisión de Patiño determinó el comienzo de un largo proceso de reconstrucción del conjunto, destinándose para la misma toda clase de efectivos humanos y materiales. La duración de esta reconstrucción (a menudo considerada por los estudiosos del tema como la única etapa constructiva que ha tenido el Fuerte de La Concepción ${ }^{4}$ ), en contínua evolución y perfeccionamiento, se extiende a lo largo de, al menos, treinta años ${ }^{5}$.

Los ingenieros militares -Moreau, Bordan, Courten, Bordick, La Ferriere ${ }^{6}$ - y los asentistas y maestros de obra - Salvador Puig, Manuel de Larra Churriguera ${ }^{7}$ - que trabajan en esta fase de las obras de la fortificación son, en aquellas fechas centrales del siglo XVIII, los expertos más cualificados e innovadores en la aplicación del sistema Vauban, introducido en España a través de las enseñanzas impartidas en la Real y Militar Academia (1710). Como tales expertos, realizan también muchas de las obras de este carácter más importantes de la Península (Cádiz, Campo de Gibraltar, el perímetro fortificado de Badajoz...). Otros ingenieros proyectistas trabajaron también sobre el modelo de La Concepción, emitiendo sus informes, a menudo desde la Corte o desde sus puestos en otros trabajos de fortificación, en los que estaba empeñado el Estado; entre ellos pueden contarse el célebre tratadista Ignacio Sala o uno de los remodeladores de Ciudad Rodrigo: Juan Martín Cermeño.

\section{El laboratorio militar}

El Fuerte de La Concepción, debido a la intervención en su fábrica de tan señalados arquitectos, fue un banco de pruebas donde se ensayan, 
en un primer momento, viejos modelos defensivos, los cuales, ya dentro del siglo XVIII, se transforman en un perfecto tejido de elementos defensivos coordinados dentro de una planta equilibrada, perfecta, ideal, identificable a simple vista con los presupuestos arquitectónicos de la era de la Ilustración. Este tipo de construcción debe ponerse, pues, en relación con otras creaciones paralelas llevadas a cabo en ambos continentes por la llamada Escuela de Fortificación Hispanoamericana ${ }^{8}$; formada en su casi total integridad por los ingenieros salidos de la Real y Militar Academia. Esta última es en su género una de las primeras instituciones ilustradas con que la monarquía Borbónica intenta la reforma interna del ejército ${ }^{9}$.

La abundante documentación que sobre la obra de Aldea del Obispo existe en el Archivo Histórico Nacional, en el Archivo Histórico Provincial de Salamanca y en el Servicio Histórico Militar demuestra la existencia de un proyecto de construcción todavía más ambicioso del que hoy podemos rastrear sobre el terreno. Las tomas aéreas del conjunto permiten también observar en toda su grandeza las huellas de un gigantesco plan constructivo, destinado a convertirse en emblema de la firmeza española frente a Portugal. Los signos de esta voluntad de la monarquía española por salvaguardar sus fronteras se concentran particularmente en la Puerta Principal del Fuerte, lugar donde pervive todavía un interesante programa iconográfico de tipo militar. Todo este conjunto de fortificaciones (camino cubierto, reducto de San José, cisternas, fosos, escarpas, cuartel de caballería, cuarteles a prueba de bomba...) y, de modo especial, el cuerpo central con la imponente puerta y cuerpo de guardia, diseñados y construidos fundamentalmente por Pedro Moreau y Manuel de Larra Churriguera, ofrecen una tipología única de arquitectura militar, en razón de la variedad y concentración de sus elementos.

Por otra parte, los valores históricos de esta arquitectura son tales, que el Fuerte de la Concepción resume en sí mismo, a lo largo de trescientos años, la conflictividad en la frontera de Castilla y Portugal, la zona de mayor protagonismo en las guerras mantenidas contra este país en los siglos XVII y XVIII, y la posterior Guerra de la Independencia. Las campañas militares en las que el Fuerte tuvo un preponderante valor estratégico fueron muy numerosas en los siglos XVII, XVIII y XIX. El Fuerte fue, primero, una posición fuerte cuando los portugueses invaden la región en un frente que iba desde Hinojosa y Ledesma hasta Guadramiro, Vitigudino y el Campo de Argañán. El duque de Berwich, con su ejército de doce mil hombres, se estacionó en aquel lugar entre los años 1703-1706. El Fuerte sería también en aquellos 
años tomado por las tropas de Lord Galway en su avance hacia Salamanca. En 1762 el Conde de Maceda inició desde esta plaza fuerte y desde la vecina Ciudad Rodrigo una ofensiva sobre Almeida. En 1801 es el mariscal francés Leclerc quien estaciona tropas en La Concepción como parte de su campaña contra Portugal. En los primeros momentos de la Guerra de la Independencia el Fuerte cambia de ocupantes en numerosas ocasiones; el general inglés Moore, también Wellington, los mariscales franceses Ney, Massena, Junot, Marmont, el duque de Abrantes, fueron a lo largo de la Guerra sus moradores, a veces en calidad de prisioneros. Finalmente, el general inglés Crawford inutilizaría la fortaleza, el 20 de julio de 1810, dejándola en el estado en que puede ser visitada hoy ${ }^{10}$. En todo lo que hoy sobrevive de la antigua fábrica del Fuerte de la Concepción se encuentra la mano de los ingenieros mencionados, los cuales intervinieron en la reconstrucción dieciochesca de muchos de sus elementos.

Pedro Moreau fue, sin duda, el más importante de los ingenieros que trabajaron en el Fuerte, a él se debe la totalidad del proyecto de remodelación y la intervención activa en las obras del mismo en calidad de coronel e ingeniero jefe. Una síntesis apresurada, como la que voy a realizar, de los distintos legajos que contienen nombramientos, encargos, destinos, etc., relacionados con la ingeniería militar, demuestra la variedad de sus actuaciones y el carácter vanguardista que sus concepciones arquitectónicas tuvieron, singularmente en el caso de las construcciones que planeó para Aldea del Obispo ${ }^{11}$. Moreau nace en Bayona, lo cual no deja de ser significativo, por cuanto confirma el hecho de que Felipe $\mathrm{V}$ gustara de rodearse de ingenieros militares franceses - seguidores, en líneas generales, de las teorías del famoso Vauban - para emprender la reforma de todo el sistema defensivo del reino. En 1727 lo encontramos citado en el Plan General de Destinos presentado por Verboom con la distribución de todos los ingenieros, apareciendo en dicha relación en calidad de jefe de una unidad técnica, encargada posiblemente de la fortificación de Pamplona. En 1729 recibe orden de partir con destino a Canarias, lugar a donde, finalmente, no debió incorporarse. Su situación de disponible le acarreó graves inseguridades, pues se conserva una carta suya, dirigida al gobernador de Navarra, quejándose de no haber recibido en los cuarenta últimos meses - la carta está fechada en 1732- ni un maravedí del sueldo que se le debía. Cádiz fue su siguiente destino y aparece allí, en 1732 , encargado de realizar algunas obras en el importantísimo sistema de fortificaciones marítimas de esta ciudad. Dos años más tarde aparece también en los documentos relacionados con las obras de la plaza de 
Badajoz. Por fin, en 1735, se encuentra ya en Ciudad Rodrigo en calidad de «delineador», siendo a partir de esta fecha cuando recibe el encargo completo de remodelar el antiguo Fuerte de la Concepción y su reducto de San José ${ }^{12}$.

1735 es, entonces, la fecha para el inicio de las obras de reconstrucción del Fuerte, y Pedro Moreau el principal ingeniero que va a intervenir en las mismas. El principal, pero no el único ni el primero, antes de que una orden de 29 de abril de ese año le comisione para el reconocimiento de las plazas de la raya fronteriza lindante con lo que es hoy la provincia de Salamanca, el primitivo Fuerte es objeto de unos primeros trabajos que tratan de acondicionar lo que fue una posición estratégica importante en la década de los sesenta del siglo XVII, y luego, posteriormente, durante la Guerra de Sucesión.

El primer expediente que se conserva sobre el restablecimiento del Fuerte, consigna el estado en que en ese entonces se encontraba la obra del Duque de Osuna, al tiempo que da cuenta de las pequeñas obras que ya se habían emprendido:

...Y aunque este fuerte consiste en un pequeño cuadrado regular de solas 80 tuesas de polígono exterior se ha formado el proyecto augmentándole revellines y un reducto, y dispuesto de suerte que tenga alojamiento para 650 Infantes, 200 caballos, sus oficiales y los Estados mayores.

Para poner este fuerte en una primitiva defensa como lo queda, se han abierto sus fosos, hecho el camino cubierto rebistiendo su parapeto de cal y canto ${ }^{13}$.

Esta primera intervención en La Concepción debió parecer, sin duda, insuficiente al mismo Patiño o a los miembros del Consejo de Guerra, que cursan en abril de 1735 unas Instrucciones que devera observar el Coronel y Ingeniero en Gefe de los Exercitos Plazas y Fronteras de S. Magestad, D. Pedro Moreau para el reconocimiento de la Plaza de Ciudad Rodrigo, y toda la Frontera de Castilla, y es como sigue... El objetivo final de esta comisión, como se revela enseguida, es el de informar sobre el estado del Fuerte de la Concepción y considerar las ventajas de su nueva utilización:

Hechas estas diligencias pasará dicho D. Pedro Moreau al Campo de Argañán, en cuio paraje hubo en el siglo último pasado un fuerte llamado de la Concepción... ${ }^{14}$. 


\section{La ingeniería militar ilustrada y la frontera de Castilla}

Se trata, en realidad, de ponerlo de nuevo «en estado de resistencia», y ello, como advierte muy bien Bordick, que es quien cursa las instrucciones, «con la armonía que requiere la profesión» (de ingeniero, se sobreentiende).

Junto a Moreau, en las Instrucciones..., aparecen los nombres de otros dos ingenieros, que después no vamos a volver a ver relacionados con las obras de Aldea del Obispo: Juan Bautista Saboyno y Joseph Berrugal, y un tercero, Bordan, del que sí cabe sospechar que interviniera decisivamente, al menos en lo que se refiere al levantamiento de los primeros planos y la constitución de los primeros proyectos ${ }^{15}$.

Estas órdenes que hemos revisado, se ven complementadas rápidamente por otras emanadas de la Corte, situada a finales del mayo de ese año en el Real Sitio de Aranjuez, y dirigidas a Felipe Dupruy, gobernador militar de la provincia. En ellas, se prevee ya la adscripción a las obras del Fuerte de un nuevo ingeniero -J. Amador Courten - ${ }^{16}$, así como la formación de un proyecto más ambicioso: la fortificación deberá ampliarse haciéndose capaz para, al menos, dos batallones y quinientos caballos.

El documento contiene, además, una importante referencia que afecta a lo que fue la génesis misma de la idea de reconstrucción de $L a$ Concepción. Sería, según ello, desde la propia Ciudad Rodrigo desde donde se habría solicitado a Patiño la restauración del Fuerte, como una manera de completar el sistema defensivo de toda la zona de la que es cabecera la ciudad del Agueda, prestándole una nueva cobertura. Se trata, en definitiva, de volver, casi cien años después, a los mismos planteamientos surgidos a raíz de la secesión portuguesa:

Deseando S.M. attender a las instancias que el cavildo de esa ciudad [Ciudad Rodrigo] hizo en el año próximo pasado en la solizitud del restablezimiento de un antiguo fuerte que por las pasadas guerras cubría el Campo de Argañán... ha resuelto... ${ }^{17}$.

El informe que, sobre el estado militar en que se hallaba el Campo de Argañán en el año 1735, eleva Pedro Moreau, acompañado de Juan Amador Courten y del Comandante General de la Provincia, Felipe Dupruy, es una de las claves para entender el porqué de la reconstrucción de La Concepción, además de ofrecer valiosos datos sobre el estado económico y social de toda la zona. El texto de siete folios, Reconocimiento y visita de la frontera de Castilla, y Portugal, egecutada en el contiguo Campo de Argañán por el Coronel e Yngeniero en jefe D. Pedro Moreau... ${ }^{18}$, recoge, como principal recomendación, la necesidad de acabar con el contrabando y las depredaciones a las que estaba sometida la desguarnecida frontera: 
[Será preciso] vigilar los desfiladeros, y finalmente cortar el ilizito comerzio que cada día practica aquella Potenzia, en el corte de la madera de los Montes altos y vajos, señaladamente la Plaza de Almeyda, la qual no puede subsistir sin estta libertada facultad ${ }^{19}$.

El objetivo del reconocimiento sobre el terreno que lleva a cabo Moreau, es el de determinar una serie de puntos susceptibles de ser fortificados, para acabar con la ruina económica y la despoblación que afectaba al Campo de Argañán en esos momentos:

Y finalmente con esta disposizión, se ampara y se cubre, y se protegerá la maior parte de los Pueblos de dicho Campo de Argañán, sostenido, y dándose la mano con los puestos fortificados quese propone establezer ${ }^{20}$.

$\mathrm{El}$ análisis económico que se practica sobre la zona es muy negativo, y se insistirá en numerosas ocasiones en compararlo con la situación diferente que habían vivido esas mismas tierras en el siglo pasado, cuando la inmediatez de la segregación portuguesa forzaba al mantenimiento de todo un ejército, a cuyo amparo se había desarrollado grandemente la agricultura y la ganadería.

Moreau no encuentra sino despoblación y ruina, concibiendo las obras de fortificación, no tanto en función de una defensa hipotética, como de una condición de estabilización territorial, que hará volver a los habitantes y desarrollará sus formas de vida:

El territorio de dicho Campo de Argañán es fertilísimo y abundante de fuentes, produziendo todo género de granos, viñas y olivares, esttas dos qualidades han sido abandonadas en su plantazión y cultibo, antes bien se han deteriorado las que antíguamente permanecían, por el miedo y poca seguridad que tienen y han tenido los Pueblos, de recoger estos fruttos, escarmentados de las invasiones, y atropelías que han experimentado en las últimas guerras, desuerte que actualmente se han reduzido a aprovecharse aunque con bastante temor a la siembra de granos, y aloque la tierra da de sí, consistiendo en enzinas, robles, pinos, que forman sus dehesas, con las yerbas, y praderías, correspondientes a pastos mui abundantes para ganado bacuno, y menudo, cuio número aunque al presente limitado por la aniquilación, y deterioro de dichas villas, y lugares, con los menzionados motivos yba expresado en el Estado general del Vezindario de dichas Villas, y lugares ${ }^{21}$.

... La tierra es impracticable de ponerse en uso enteramente, por los pocos vezinos que subsisten, que aseguran que en lo antiguo, y era opulentta en que florecía estte mencionado País, contenía dos terzeras partes más de vezinos que oy subsisten, como se ve patentemente por el número de Casas, y havitaziones demolidas, arruinadas, que cada villa y lugar manifiesta, cuio descaezimiento empezó por las invasiones 


\section{La ingeniería militar ilustrada y la frontera de Castilla}

que tengo referido, y siempre ha proseguido, o sea por estte motibo, o por el de las malas cosechas alternando el uno y el otro siempre en perjuizio, y en notable detrimento de los Vasallos de S.M. y de las rentas Eclesiásticas del Cavildo de Ciudad Rodrigo ${ }^{22}$ sin tener recurso alguno que otros suelen tener con la aseguranza de no estar expuestos a invasiones de guerra, o sea por tener granos en provisión que suelen dejar para este fin, vajo de esta seguridad, o sea por la cosecha de otros géneros como vino, y azeite, la qual sería considerable en este territorio, pudiendo estableçerla en maior abundanzia en lo venidero, una vez que dichos Pueblos estubiesen asegurados, y amparados de las fortalezas y Armas del Rey... ${ }^{23}$.

La opinión de Moreau y Courten resulta favorable a la construcción de una red de defensas que tenga como principal virtud la de marcar, con una acción poderosa del Estado, lo que son las fronteras y límites del Reino, sobre los que hay, todavía, una cierta indefinición. Por eso se piensa en construir estas fortificaciones, entre las que el Fuerte de la Concepción parece un puntal básico, sobre la línea misma de demarcación entre las dos naciones:

Nos pareze conveniente ocupar algunos de ellos fortificándolos afin de que uno a otro se den la mano, y defiendan como primera línea contra qualquier arrojo del Reyno vezino... ${ }^{24}$.

Esta parece ser, en esos momentos, la única manera de poner fin a una curiosa situación que denuncian en sus observaciones los ingenieros:

...Y de lo contrario, se experimenta la aniquilazión de dichos vezinos, pues ha llegado el caso por no bastar estos, en el mismo País, que los Dueños y Propietarios de las heredades arriendan la maior parte de las tierras para sembrar dehesas y Pastos a los Portugueses, asta hallarse havitados la maior porzión de los lugares inmediatos a la frontera, por estta misma Nazión, como lo hemos visto en la Alberguería, Puebla, Alamedilla, Fuentes de Oñoro, Aldea del Obispo, Campo Redóndo y Barba de Puerco, lo que es contra el decoro, y honor del Reyno, y en perjuizio de sus Pueblos, deviéndose considerar y rexelar por el amor que siempre llevará estta Nazión a su patria... ${ }^{25}$.

La línea fronteriza a establecer se delimita con precisión en el escrito. Comienza en Alberguería de Argañán, donde Moreau reseña la existencia del viejo castillo, demolido por los portugueses en fecha imprecisa. La pequeña cordillera que llega hasta cerca de Ciudad Rodrigo defiende, hasta cierto punto, según las apreciaciones del ingeniero, el territorio por esta parte. En Fuentes de Oñoro, por ser una zona 
tradicional de batidas portuguesas, dada la facilidad que ofrece el terreno, Moreau recomienda el establecimiento de un «puesto fortificado para doscientos hombres de guarnición».

El informe no se limita a ofrecer el esquema básico de lo que habría de ser la nueva defensa del Campo de Argañán, sino que entra en el análisis de las líneas y plazas fortificadas establecidas en el pasado, y que no habían sido trazadas desde una racionalidad estratégica:

...Asta la Alameda, a cuia distanzia de un quarto de legua acia el fuerte de la Concepción, se halla situado un castillejo también arruinado por los portugueses, llamado del Gardón, dominado por todas las alturas circunvezinas, y por consiguiente inútil, maiormente teniendo a media legua de distanzia, sobre la derecha siguiendo la misma cordillera, y situado sobre ella, el fuerte antiguo de la Concepzión... ${ }^{26}$.

En esta primera mención al Fuerte de la Concepción en el informe, se dice que ocupa el emplazamiento ideal para el tipo de fortaleza que la Corona desea construir. Advirtiéndose también allí que los terraplenes del viejo fuerte "subsisten todavía a una razonable altura».

Las propuestas que completan este primer diseño de la puesta en defensa de la Frontera de Castilla hacen referencia a la fortificación del puente del río Agueda, en la zona en que desemboca el Turones, y a la construcción de un reducto en la altura entre Barba de Puerco y Boza. El dispositivo se completa en esta zona con unos puestos de retaguardia, que tienen controlado visualmente el territorio, en especial con la atalaya que se propone en la ermita de San Cristóbal.

Para la eficacia de lo aquí descrito, tanto Moreau como Courten confían, sin embargo, sobre todo, en que la reconstrucción del fuerte levantado en una primera instancia por el Duque de Osuna será llevada a cabo sin dilación. El emplazamiento resulta clave por su situación como avanzadilla; por el terreno enemigo que bate y por la función que puede cubrir en cuanto a centralizar toda la línea defensiva situada a sus costados:

Por lo que me parece mui esencialissimo la Restauración de dicho Fuerte cuia figura consiste en un quadrado y se puede seguir su construcción dándole ochenta mesas de frente, construyendo en el terreno o loma de la izquierda más elevada que dicho fuerte de diez a doze pies, un pequeño reducto a fin de guardar el acceso a la principal fortificación lo que me parece suficiente contra dicho Reino vecino ${ }^{27}$.

En este punto, el informe evidencia una de las contradicciones de diseño de ingeniería que la edificación arrastra desde su primer mo- 


\section{La ingeniería militar ilustrada y la frontera de Castilla}

mento fundacional. Efectivamente, la plaza de armas aparece a menor cota que la loma, donde en la actualidad se asienta el reducto de San José. Esa desproporción pudo ser la causa de la rápida neutralización de la fortaleza en los años 1663-1664, y, desde luego, es el origen de la posterior preocupación de todos los ingenieros que pasan por ese destino en fortificar convenientemente, no sólo la plaza o fuerte, propiamente dicho, sino también el reducto.

De esta observación que realiza en el año 1735 Moreau, parte, también, su empeño en construir un módulo intermedio el que será polémico cuartel de caballería-, que apoye tácticamente a la zona de enclave del reducto, y que impida, en el caso probable de su toma, un ataque por ese lado. Esta idea de una secuenciación de estructuras defensivas a lo largo de un eje (el camino cubierto) lo veremos aparecer siempre en todos los informes que sobre el Fuerte emite el ingeniero a través de los años.

Presa entonces de carencias estructurales ${ }^{28}$, el conjunto arquitectónico de $L a$ Concepción va a sancionar, con una historia militarmente señalada por el fracaso de los rendimientos que de su dispositivo se esperan, esta primera observación de Moreau, quien, como hemos visto, defiende pese a ello la decisión de reconstruir el Fuerte.

Rebasada la zona del Fuerte de La Concepción, y dirigiéndose al norte, Moreau y Courten informarán sobre el castillo de San Felices de los Gallegos, levantando un plano minucioso con todas las defensas de la villa; plano topográfico que se completa con una representación en sección de la torre, debida a Diego Bordick.

En los planes estratégicos de esos años, San Felices siempre fue considerado como uno de los centros tácticos de importancia, como avanzadilla y, a la vez, cobertura y defensa de Ciudad Rodrigo. Por esta razón se realizaron obras de remodelación de su perímetro en el primer tercio del siglo ${ }^{29}$, y por esta razón, también, un ingeniero de la talla del francés Robellin, ingeniero director sin patente ${ }^{30}$, realizó el plano de la torre del castillo de San Felices en 1722. Finalmente, Ledesma, en la retaguardia, se presenta también como uno de los puntos neurálgicos para la defensa de la Frontera de Castilla:

Además, que este puesto será esencialísimo para el abrigo, y cubrir la comunicazión de todos los puestos, y parages de dicho Campo, para qualquier movimiento de nuestros destacamentos, así de Cavallería, como de Infantería, dándose la mano con esta Capital, y el castillo de San Felizes... ${ }^{31}$.

La visita de Pedro Moreau al Campo de Argañán concluye el dos de julio de 1735 y se conserva un documento firmado por Bordick, 
en fechas siguientes, en que una vez conocido el informe, sugiere al Consejo que sea Courten el que se encargue de las obras del Fuerte, acompañado de otro ingeniero que había trabajado con Courten en Venezuela en las obras del fuerte de San Felipe de Puerto Cabello: Antonio Jordán ${ }^{32}$.

El 26 de julio, Bordick envía a Patiño un texto acompañado de una representación gráfica, que podemos considerar (y así queda consignado en el plano: primera y principal traza del Fuerte...) como el primer proyecto de la reconstrucción dieciochesca del Fuerte de La Concepción.

La planta de esa construcción propuesta por Bordick es pentagonal y se superpone, con una articulación compleja heredera en todo del sistema Vauban, a la primitiva planta cuadrangular, que queda también englobada en el proyecto, con una insistencia especial en el hecho de que de ninguna manera seria destruida:

Yo tengo ya proyectado por mayor, con una disposición de mi satisfacción en quanto a las defensas, a saver, un pentagono, cuio cuerpo de plaza estará cubierto enteramente de cinco contraguardias... forman un doble recinto... ${ }^{33}$.

Junto con el proyecto, Bordick remite un balance de las necesidades económicas y un inventario de los materiales que se necesitan, que, entretanto, han comenzado ya a trasladarse a pie de obra por una orden de comienzo de los trabajos dada el 24 de julio de 1735 , y que podemos considerar como la fecha absoluta de comienzo de reconstrucción de La Concepción.

Un apartado interesante dentro del proyecto de Bordick, lo constituye el documento De la Artillería, Municiones, Pertrechos y Utiles para la defensa del nuevo Fuerte..., que da idea de la magnitud que se le pretende dar a la fortificación de Aldea del Obispo, destinándose, por ejemplo, ochenta cañones para el artillado de la plaza de armas.

En septiembre de 1735, el estado de las obras iniciadas determina la presencia en Ciudad Rodrigo de Dupruy, que libra varias cartas para prevención de materiales, en las que queda constancia de las primeras estimaciones económicas sobre el costo del Fuerte: «36.000 escudos de vellón gaso previsto para las primeras obras».

Courten mismo, también, redacta dos informes que sugieren que va a ser él -y no ya Moreau- quien, conforme a los deseos de Bordick, se va a encargar de La Concepción. Son un Tanteo prudenzial de lo que podrán importar las obras de la rehedificación... (septiembre de $1735)^{34}$ y el Pliego de Condiziones a las quales los que emprendiexen... 
(octubre de 1735) ${ }^{35}$. En el segundo de los dos textos, Courten menciona al maestro de obras Gabriel Puig, que un año después se encargará del cuerpo de entrada principal, y que por aquellas fechas se encontraba trabajando en las fortificaciones de Badajoz ${ }^{36}$.

Los planos remitidos por Bordick debieron inducir a los miembros del Consejo a conceder una mayor importancia, de la que en principio se proyectaba, a las obras de fortificación ya comenzadas en Aldea del Obispo.

La orden de Patiño recibida por Bordick explicita que:

En lugar de la obra provisional que se tenía ideado para restablecer el Fuerte de la Concepción se efectúe en las formas, rebistiendo de murallas, y haciendo firmes y estables los Cuarteles; Almacenes y demás edificios ${ }^{37}$.

Sin embargo, por la carta de contestación de Bordick a Patiño, de 3 de noviembre de 1735, sabemos que, si bien existe la intención de consolidar con los «medios que previene el Arte» el Fuerte de La Concepción, prácticamente se ha rechazado el proyecto de una planta pentagonal. Este rechazo obliga a Bordick a reconsiderar su primer proyecto, circunscribiéndolo ya a las dimensiones y trazado del que existía desde los tiempos del Duque de Osuna:

En bista de que, si es que S.M. no resuelve la construcción del Pentágono que propuse avra de ser a lo menos un quadrado de 140 tuesas ${ }^{38}$.

El 8 de noviembre se le contesta a Bordick que se practique obra «en todo proporcionada a las dimensiones que actualmente se halla el cuerpo del referido fuerte», y el 22 de ese mismo mes Bordick remite 'el proyecto final del Fuerte.

En este punto sobreviene uno de los muchos cambios importantes por los que atraviesa el proyecto constructivo. A partir del envío de los planos de Bordick, éste es apartado de las obras temporalmente, mientras el Consejo determina la rápida incorporación de Pedro Moreau a su puesto de ingeniero en la Frontera. Es, finalmente, a Moreau a quién, en despacho de 30 de noviembre de 1735, y encontrándose el ingeniero en ese momento en la Corte, se le encomienda el levantamiento de nuevos planos y, en definitiva, de un proyecto general para $L a$ Concepción.

Entretanto, la construcción del Fuerte se ve impulsada de nuevo desde Ciudad Rodrigo, donde el Cabildo, el Ayuntamiento y el «estado noble» hacen una oferta de caudales con destino a la obra. En este sentido, debemos entender también como definitivas, para la suerte 
del gigantesco complejo de fortificaciones alzado en Aldea del Obispo en aquellos años, las disposiciones - todas del año 36- conducentes al restablecimiento del lugar de Aldea del Obispo.

La repoblación y una serie variada de medidas de índole administrativa — como la creación de una aduana- van a suministrar, en adelante, una cobertura civil: en definitiva, una población renovada -después del fenómeno de despoblación descrito por Pedro Moreau en su Informe- va a nacer a la sombra del dispositivo militar que en esos momentos comenzaba a alzarse sobre un territorio conflictivo desde siglos atrás.

El proyecto de Moreau para el Fuerte cristaliza en unos pliegos de Condiciones para el asiento de las obras del mismo. Firmado por el ingeniero director y coronel, en abril de 1736, este documento da una idea muy completa de lo que se pretendió y realmente se llegó a construir entonces. Su parcial transcripción aquí puede suministrar una visión general del sistema de construcción empleado en el siglo XVIII para fuertes y complejos defensivos ${ }^{39}$.

\section{Pliego de condiciones}

Condiciones según las quales se procederá públicamente por parte de S.Mg. á la adjudicación de la construcción del Fuerte Real de la Concepzión, y su redutillo, situado en el Campo de Argañan, conpuesto dcho Fuerte de quatro baluartes y quatro revellines con su comunicacion á dcho Redutillo, fosos, camino cubierto, esplanada, parapetos, banquetas, espaldones, quarteles á prueva de bomba, con todo lo demás perteneciente y respective a dcha fortificación en la forma que esta empezado, y lo demostrará el plano y perfiles que se exiviran a este fin.

El texto completo aparece firmado por Pedro Moreau, en el Campo de Aldea del Obispo, el 19 de abril de 1736.

En este mismo año de 1736, alcanza Pedro Moreau el empleo de coronel, con destino en La Frontera de Castilla. Esta primera fase en la reconstrucción de La Concepción bajo su directa supervisión duró exactamente hasta el 3 de diciembre de 1740, año en que cesa, siendo sus siguientes obras documentables aquellas que realizó en Orán (donde se encontraba en 1747) y las del Campo de Gibraltar, en 1749. Un año después, en 1750 , concluye el alejamiento impuesto a Moreau con respecto a las obras del Fuerte; destinado de nuevo a la Frontera de Castilla, continúa en Aldea del Obispo con las obras que habían comenzado, quince años atrás, bajo su dirección. En 1757 Moreau aparece ya desligado definitivamente de La Concepción. Lo encontramos des- 


\section{La ingeniería militar ilustrada y la frontera de Castilla}

tinado en Zamora, ciudad para la que existe un proyecto por él firmado para la construcción de unos cuarteles ${ }^{40}$.

El último documento que he revisado sobre Pedro Moreau es una petición de retiro cursada en el año 1760; en el texto de esta misma petición queda constancia de cómo Moreau deja a Pedro Bordán en calidad de sucesor suyo al frente de las obras del Fuerte de La Concepción.

Poco después de la publicación del Pliego de Condiciones, el 1 de mayo de 1736, se pone la primera piedra del Fuerte, acontecimiento sobre el que nos queda un detallado documento, conservado en la parroquia de Aldea del Obispo:

Oy primero de Mayo de Mil setezientos treinta y seis, Dia de San Phelipe y Santiago: Reinando Phelipe quinto, que Dios guarde, Rey Cathólico de las Españas en el treinta y seis de su reynado, e Isabel Farnesio, que Dios guarde, Reyna Cathólica de las Españas... Hallándose primer ministro de S.M. el Excmo. D. Josep Patiño en el mismo año en que se conquistó por las armas de S.M. el Reyno de Nápoles y de las dos Sizilias, y se retiraron después de estas conquistas las tropas del Rey a España; Dieciocho años después que se fabricó la Ziudadela de Barzelona, por el ingeniero general, el Marqués de Borbón Verboom y actual Gobernador de ella Theniente general o Quartel Maestre general de la Monarquía; cuatro años después de la conquista de Orán. Siendo Gobernador de la Plaza de Ziudad Rodrigo, y Comandante general de este Exercito y Provincia Don Phelipe Dupuy e Intendente de la misma Provincia, el marqués de Arellano, se puso la primera piedra, en el ángulo flanqueado del camino cubierto del Revellín entre el valuarte del Rey, y de la Reyna, frente que mira a Portugal, del Fuerte real de la Concepción, situado en una eminenzia, distante del rio Turones que sirbe de límites de este Reino y el referido de Portugal a poca distancia del lugar de Aldea del Obispo, districto del Campo de Argañán, habiéndose empezado esta fortaleza desde prinzipio de este Año por la direczión del Coronel de Infantería, D. Pedro Moreau, Ingeniero Director de los reales Exércitos de S. M., asistido de los Ingenieros Don Juan Foucaviti, D. Pedro Bordán, D. Pedro Leco y D. Hernando Hontabatt. Intirviniendo en los caudales de S. M. D. Lesmes Pedro Garzia Sagrido, Secretario de SM. a cuio fin, se zelebró en hazimiento de Grazias el Santo sacrificio de la Misa en el Oratorio inmediato a dicho Fuerte... prezedida de una Procesión a que asistieron dichos Ingenieros, comisario de Guerra y mucho concurso de gentes y puesto en armas el destacamento aquí destacado, de Nobenta hombres del Reximiento de Milizias de Ziudad Rodrigo con sus ofiziales correspondientes; y en esta forma se transfirieron, desde dicho oratorio, en el referido paraxe destinado para la colocazión de dicha Piedra. La cual después de ven- 
dezida con el terreno y contorno a dicho Fuerte se colocó en dicho ángulo flanqueado por D. a Saturnina de Lieson Moreau, mujer del referido Ingeniero Director, cuia Zeremonia y Zelebración se executó con tres salbas de fusilería... ${ }^{41}$.

El trabajo de Moreau en La Concepción es largo y concienzudo; se encuentra trenzado de múltiples consultas, de rectificaciones y de reelaboraciones realizadas por él mismo o en colaboración con otros ingenieros.

Los detalles de la construcción son discutidos hasta la exasperación: son, en un principio, las bóvedas de los cuarteles a prueba de bomba en la plaza de armas las que suscitan, en 1737, varios cruces de cartas entre el Consejo y Moreau, problema en el que interviene, como ingeniero consultado, Juan de La Ferriere ${ }^{42}$. Más adelante, desde octubre de 1737, es la Real Junta de Fortificaciones la que va a intervenir, siguiendo muy de cerca, y en ocasiones determinándolas, las modificaciones que se van introduciendo en los primitivos diseños de Moreau.

Así tenemos, por ejemplo, cómo esta Junta, con criterios ahora puramente decorativos o, en general, artísticos, realiza precisiones al diseño de puerta remitido por Moreau, en el sentido de proponer que las pilastras que flanquean la estructura arrancaran desde la misma base, en orden, como se explicita, a respetar los principios constitutivos del estilo dórico. En este mismo sentido, se propone suprimir la poterna de la puerta principal, cosa que finalmente, como puede hoy comprobarse en las mismas ruinas, no es llevada a cabo en el diseño de Larra Churriguera.

La Puerta Principal de la Plaza de Armas de La Concepción, a la que desde un principio, y por expresa decisión del Consejo de Guerra, le está encomendada la representación misma de la decisión del Estado en rearmar y proteger los dominios amenazados de su soberanía, es uno de los puntos centrales, en torno al cual gira el largo proceso constructivo que sigue la fortificación. Para Soraluce, «de todos los elementos que forman el complejo de los proyectos de fortificación, es en las puertas donde los ingenieros dejaron la huella de su buen gusto y demostraron su capacidad técnica para resolver el punto más conflictivo y difícil de toda la obra. Por ello, en todos los proyectos de Arquitectura Militar aparece diseñada a escala mayor y perfectamente definida la portada. El cuidado y detalle con que se proyectaban dan la nota de belleza y sensibilidad artística en estas obras que por sus dimensiones y complejidad difícilmente podían apreciarse en conjunto» ${ }^{43}$.

Múltiples aspectos se anudan en la arquitectura de las portadas principales, entre ellos: la mencionada representatividad, política y 
militar, de la población a la que dan acceso o al reino al que pertenecen; la plasmación estética del gusto de la época; las dimensiones idóneas para facilitar tanto un tránsito como para servir también de elemento defensivo, en combinación con el conjunto; resistencia a la artillería frontal; solución de su conexión con la explanada exterior; aislamiento total de la muralla con el exterior. mediante el puente levadizo; distribución en su derredor del cuerpo de guardia. calabozos, polvorines...

Las resistencias encontradas por el primer $-\mathrm{y}$, al parecer, excesivamente simplista - proyecto de Moreau van a determinar que un nuevo experto - esta vez no ingeniero- intervenga decisivamente en el Fuerte: Manuel de Larra Churriguera.

La participación de Larra Churriguera en la segunda etapa constructiva del Fuerte de La Concepción, abierta en 1735, ha sido señalada por distintos investigadores, no sin algunas contradicciones y siempre, hasta la fecha, sin aportación de los documentos que pudiesen fijar en qué consistió tal intervención ${ }^{44}$.

El encuentro en un protocolo notarial del A. H. P. de Salamanca de los pliegos de condiciones, autos, licitaciones y allanamientos, que con motivo de la concesión de las obras de restauración del Fuerte se hicieron entre los años 1736 y $1737^{45}$, y la existencia en el A. H. $\mathrm{N}$. de dos planos y una carta firmados por Larra Churriguera ${ }^{46}$, esclarecen de un modo definitivo la clase de intervención que el arquitecto y maestro de obras tuvo en el Fuerte.

A la luz de los documentos del A. H. P., se deduce que Manuel de Larra Churriguera licitó para maestro de obras del conjunto defensivo que se estaba reedificando en esos momentos en Aldea del Obispo, desde el 1 de noviembre de 1736 hasta el 12 de febrero del año siguiente. Su pretensión al cargo - Gabriel Puig y Valentín de Medina, que lo habían ostentado con anterioridad, terminan en la cárcel por incumplimiento de sus compromisos contractuales ${ }^{47}$, suscita muchas vicisitudes vencidas, finalmente, al ser apoyada la fianza que presenta Larra Churriguera por el Marqués de Arellano, Intendente General del Ejército. La serie de planos y cartas cruzadas entre los ingenieros militares que colaboran en la reconstrucción del Fuerte y el Gobernador General de la Frontera de Castilla, conservados en el A. H. N. ${ }^{48}$, evidencian cómo el proyecto de reconstrucción del conjunto pertenece casi por entero al ingeniero Pedro Moreau. Dos de estos planos y una carta dirigidos al Duque de Montemar demuestran, por otra parte, cómo la intervención de Larra Churriguera se concretó en la construcción de una de las partes vitales del Fuerte: el cuerpo central con la puerta principal y entrada. 
Planos y carta patentizan los inconvenientes técnicos y también burocráticos que Manuel de Larra Churriguera tuvo que vencer y las ingeniosas soluciones que dio a los primeros. Este «cuerpo central», depositario de los valores emblemáticos que como civitas belli le corresponde al núcleo de fortificaciones levantadas en Aldea del Obispo, enfatiza aún más la importancia de lo que constituye uno de los complejos defensivos de mayor interés de entre los que, pertenecientes a la arquitectura militar del siglo XVIII, aún quedan en pie en España:

Habiéndome restituido â este Real Fuerte desde la Plaza de Ziudad Rodrigo, el dia 29 de el pasado, pase inmediatamente, a reconocer las disposiciones que ócurrían en los travajos de esta Real óbra, los que encontré tan diminutos en dispossizion, que todos los operarios se me lamentavan de la falta de determinación de travajos por lo que lo más de los operarios se hallaban sin travajar, con cuio motivo recurrí con un papel al Comisario de Guerra Don Ramon Larumbe, para que mediante los trabajos que señaladamente pedía por escripto, Planos, y Perfiles, que egecute: resolbieran trabajos; y haviéndoselo hecho saver a los Ingenieros que aqui residen, respondieron: que ellos por sí no podian resolver nada, con cuio motibo recurrió dicho Comisario al Director, quien se halla en Ziudad Rodrigo, con mi papel, Planos, y Perfiles, en que proponia además depedir travajos señalados, algunas dificultades que se me ofrecen sobre el zerramiento de las bóbedas que componen el Cañon de la entrada de la Puerta prinzipal de este Fuerte, como asimismo sobre que teniendo los canteros lavrado un Arco, o medio Cañon de canteria para la primer distanzia, o tránsito que se sigue a la entrada de dicha Puerta prinzipal, el que habiendolo reparado es ympracticable el que puedan abrir las Puertas condicho corte sin tropezarse enel, porlo que sehaze preziso zerrarle con una Bóbeda de Lunetas, para que vajo de la forma de su costado, pueda doblar, y abrir la Puerta enteramente con livertad, todo lo que represente, y hize patente en mi papel, planos, y Perfiles que puse en manos de dicho Comisario; quien haviéndolos remitido a dicho Director, se los debolbio sin dar mas razon que la de que nezesitaba de seis, o siete dias para la resoluzión de todos y habiendo pedido yo esto en el Día Zinco del Corriente; y repetido otro en el día nuebe, y habiéndose pasado mas de los siete Dias, no he tenido respuesta de dicho Director de lo que se ha de egecutar, siendo asi que estas resoluziones de travajos, y más las que penden de cantería en que es nezesario disponerlas contiempo mui antizipado, porel mucho que se nezesita para su arranque, transporte, y labra es nezesario darlas mui de ante mano, para que no hagan falta a su tiempo, y temiéndome de que nos falte a su correspondiente, como mui a mi costa tengo experimentado en todas las retardadas Disposiziones de este Director; recurro a Vuecencia con el adjunto Plano, y 


\section{La ingeniería militar ilustrada y la frontera de Castilla}

Perfiles de dicha Portada Prinzipal, y toda su obra, para que mediante el estado en que se halla, que es la elevación de sus Impostas que están al arranque de los Arcos, y elección de Bóbedas, lo mande Vuecenzia reconozer, ver si segun su Disposición zerrará todo vien en la conformidad que demuestran sus Perfiles, o se me diga en la forma que lo deva proseguir, y obserbar, para egecutarlo; sirviéndose Vuecenzia demandar reparar en el modo como han de jugar las puertas prinzipales, para que se me advierta lo que deba practicar, pues de zerrar su tránsito con el medio cañón que esta labrado, se haze ympracticable el uso de las Puertas, como se puede ver en los perfiles que remito con toda su explicación, de que quedo aguardando resoluzión de Vuecenzia para egecutar lo que se me mandare y en el ynterim me repito a las órdenes de Vuecenzia, Deseando que Nuestro Señor Guarde a Vuecenzia en su maior Grandeza. Aldea de el Obispo y Henero 19 de 1739. Excelentisimo Señor. Beso los pies de vuestra excelencia, Su mas Rendido Criado, Manuel de Larra ${ }^{49}$.

Los aspectos relativos al diseño de la puerta central del Fuerte de La Concepción se completan con el alzado que, el 4 de abril de 1739, remite La Ferriere, que, a la sazón, se encontraba ya en Aldea del Obispo desde el $1 .^{\circ}$ de noviembre de $1738^{50}$.

Los tres proyectos sucesivos del módulo del cuerpo de guardia y de la propia portada de la plaza de armas de La Concepción, dan idea de la constante revisión a que se ven sometidos todos los pasos que sigue la historia constructiva de esta edificación. De hecho, los proyectos de Larra Churriguera ${ }^{51}$ y el de La Ferriere reabren, dramáticamente, si atendemos a la dilación en la ejecución de obras que ello supone, la aprobación final que el Consejo y Junta de Fortificaciones habían dado al proyecto de Moreau, en una fecha imprecisa que podemos situar entre el 24 de agosto y el 11 de septiembre de 1737. Esta aprobación ya entrañaba entre sus recomendaciones la referida a modificaciones en la casa alojamiento del Gobernador, que el Consejo entendía debía ser realizada sobre las bóvedas del cuerpo de guardia. Será finalmente el proyecto de La Ferriere el que culmine, sin afectar a todo el diseño interior y de portada, que es, como he demostrado en otro sitio, de Larra Churriguera, todo este difícil y enrevesado episodio de la construcción de la puerta principal y cuerpo de guardia del Fuerte de La Concepción ${ }^{52}$.

Aparte de la estructura de las bóvedas y de la problemática que suscita el mismo cuerpo de ingreso en la plaza, otras cuestiones arquitectónicas siguen estando a la base de una intensa corriente de consultas y documentos que evidencian tanto la complejidad burocrática, que afecta al aparato dirigente del Estado, como el cuidado y rigor 
con que se quiere proceder a crear una infraestructura de tipo militar, destinada a tener una larga utilización. Como ejemplo de ello, podemos citar la consulta que La Ferriere realiza, con el tema de fondo de las letrinas («lugares comunes») y todo el sistema de desagüe del Fuerte, a Ignacio de Sala, afamado ingeniero militar que publicará en Cádiz, en 1743, la primera edición en castellano de la obra de Vauban, Tratado de la defensa de las plazas.

Los cambios y modificaciones de detalles constructivos afectan también a la dirección misma de las obras. En una carta de La Ferriere, de 24 de abril de 1739, queda recogida la noticia de que Bernardo de Frosne ha sido encargado de la dirección de la obra. Sin embargo, Moreau sigue ocupándose de La Concepción hasta 1740, si bien, en los documentos que remite en estas fechas se observa un desplazamiento del eje de sus preocupaciones. Se ocupa ahora con sus diseños de dos puntos estratégicos para la vertebración global de los aspectos defensivos de aquel territorio.

El Cerro de la Cruz, donde se asienta hoy el reducto de San José y la construcción de unos cuarteles de caballería, a la mitad del camino cubierto que va desde la plaza de armas al reducto, son los últimos proyectos en esta su primera etapa en Aldea del Obispo. Al menos la segunda de tales propuestas es rechazada, primero por la junta Real de Fortificaciones:

Hace presente que no encuentra razón alguna para que se diviertan los raudales en la execución de los expresados quarteles ${ }^{53}$.

También Juan de la Ferriere, consultado desde Barcelona, donde se encontraba en esos momentos, rechaza la idea de construir un cuartel con dos cuerpos.

En este tiempo es todavía ingente la obra que queda por terminar en La Concepción. El gasto calculado por Bernardo de Frosne (a tres de junio de 1741) señala 1.500 .000 reales de vellón, para acudir a lo más necesario.

A partir de este informe y del alejamiento consecuente de Pedro Moreau, el principal artífice de los proyectos, existe un vacío documental de 6 años, que termina el 16 de septiembre de 1747 con un nuevo y detalladísimo informe en el que, de nuevo Moreau, que entretanto debía haber sido repuesto en su cargo en $L a$ Concepción, informa sobre la situación global del conjunto en esas fechas.

En 1747 la edificación del Fuerte sigue distando mucho de hallarse ya completa. Leemos en el informe de Moreau cómo los cuatro baluartes del Fuerte - los de la Reina y el Rey, orientados hacia Portugal, el 


\section{La ingeniería militar ilustrada y la frontera de Castilla}

del infante don Felipe y el del Príncipe, hacia Aldea del Obispo- se hallan ya construidos y rematados por garitas; las cortinas que los unen, en cambio, están terminadas sólo hasta la línea del cordón. El grupo central de acceso a la plaza tiene levantados los puentes y la misma puerta principal se encuentra rematada a la misma altura del cordón de las cortinas. El escudo principal no había sido todavía labrado y siguen sin practicarse las excavaciones en el interior de la plaza en ese año.

En cuanto a las obras de exterior, el camino cubierto, eje neurálgico destinado a vertebrar toda defensa, secuenciándola en los tres futuros módulos - reducto, plaza de armas, cuartel de caballería-, no tiene levantada la banqueta, y en cuanto al glacis, éste no se halla aún perfeccionado hasta el extremo que logre una correcta desenfilada de los tiros para el conjunto de la fortificación.

En el reducto, el arco de ingreso con un grueso bocelón, que hoy todavía se mantiene en pie, había sido ya levantado, de igual modo que estaban comenzadas las cisternas y la red subterránea, consistente en salidas secretas y complicados sistemas de desagüe.

Moreau informa, por último, de la urgencia que hay en comenzar a construir el cuartel de caballería, sobre el que todavía no se había optado por un modelo concreto. El balance de Moreau termina con una nueva referencia a los gastos que generará todavía la terminación del Fuerte: 1.400 .000 reales de vellón.

La situación de la fortificación permanece, durante esos años, estancada, sin que exista una decisión final para su terminación. Los informes aumentan y los ingenieros ofrecen nuevas plantas sobre las que los sucesivos Consejos reflexionan y, sobre todo, muestran todo tipo de reticencias de orden técnico. De la interacción de todos los criterios especializados que concurren en la obra, proviene, en buena medida, la paralización y desorientación, que fue la característica principal del modo de actuación en el conjunto.

\section{La Ilustración irresoluta}

De los informes técnicos que se conservan entre los papeles del Consejo de Guerra, destaca el documento emitido por el ingeniero Antonio de Gaver, conocido por sus trabajos en la fortificación de Orán ${ }^{54}$, Descripción del fuerte, situación, terreno de sus circuitos y bentajas que de su defensa logra la Probinzia. El texto es interesante para nuestro objeto por cuanto viene a defender la posición estratégica elegida en 
su tiempo por el propio Duque de Osuna. El Fuerte contiene las avenidas portuguesas en el Campo de Argañán; siempre y cuando que, desde el punto de vista de Gaver, paralelamente, se ponga en defensa la plaza de Ciudad Rodrigo: "pues tanto se respetará [el propio Fuerte], quanto se aga respetable aquella».

En todo caso, la necesidad misma de proseguir las obras, y aun de concluirlas, se basa en razonamientos que combinan lo táctico con lo político. Escribe Gaver:

En todas partes las fortificaziones acuerdan la autoridad del Soberano, sujetan los pueblos a la Soziedad y obedienzia, maiormente a los que habitan distante de las plazas fortificadas; cuio olbido les impide la frecuenzia con la tropa; y en cualquier caso havisan la bigilancia ${ }^{55}$.

Diversas modificaciones contiene el informe de Gaver, relacionadas, sobre todo, con el dispositivo de obras exteriores: trabajos en el glacis; construcción de tenazas; ampliación de los fosos del reducto y, especialmente, una nueva ubicación para los cuarteles de caballería que adoptan la forma de dos trapecios extendidos, en una medida variable, a ambos lados del camino cubierto que comunica San José con el núcleo de la plaza de armas.

Coincidente con la época de gobierno del Marqués de la Ensenada y los proyectos del Despotismo Ilustrado, en orden a rehacer las defensas del reino, y aprovechando el plazo de paz abierto por el tratado de Aquisgrán, se sitúa esta nueva aceleración de los proyectos de terminación de la larga obra en la Frontera de Castilla.

Más aún, el informe de Gaver del año 51, así como los planos y perfiles que levanta cinco años después, en 1756, son una consecuencia directa del Tratado de Límites firmado con Portugal, en 1750. La estabilización definitiva de unas fronteras hasta entonces siempre en litigio, conduce a Ensenada a dotar a la periferia del territorio de una organización militar estable y sólida, de la que hasta el momento había carecido.

Gaver recoge este espíritu en su correspondencia con los órganos ejecutivos del Estado:

[quedará] Demostrada la utilidad del Fuerte y circunstanzias de su establezimiento, tanto en la tranquilidad de la presente paz, como en los disturbios de la guerra ${ }^{56}$.

Estamos ya, en estas fechas de la década de 1750, ante los momentos finales del proceso constructivo del Fuerte que, sin embargo, permanecerá hasta finales del siglo sin ser rematado en su totalidad. 


\section{La ingeniería militar ilustrada y la frontera de Castilla}

Los proyectos de renovación, de extensión de lo que son sus defensas externas, continúan, sin embargo, todavía, durante esos mismos años. Nuevos ingenieros pasan por la plaza comisionados en muchas ocasiones directamente por los capitanes generales del Reino de Castilla, cuya primera preocupación al ocupar los cargos es la de concluir el Fuerte de La Concepción y rematar así un proyecto de defensa que tiene ya más de cien años.

Juan Giraldo de Chaves es otro de los ingenieros que, graduado en la Academia de Barcelona ${ }^{57}$, trabaja durante diez años, con algunas interrupciones, en la Frontera de Castilla y, en concreto, en el triángulo de fortificaciones que forman Ciudad Rodrigo, San Felices y el propio Fuerte. Su informe se conserva en el Servicio Histórico Militar ${ }^{58}$, con lo que presumiblemente es un error de fecha, ya que el documento debe ser de $1756^{59}$.

Las observaciones de Giraldo de Chaves reflejan ya lo que será el estado en que conocemos el complejo defensivo. Por un lado, el reducto se encuentra terminado y dotado de un hornabeque. El cuartel de caballería también ha sido rematado, al menos en la cara que mira hacia el este, siendo descrito en estos términos:

En su medio [del camino cubierto] está el reducto de caballería de figura de rombo, con cañoneras con dirección a todas partes, asegura y enfila este reducto la comunicazión de San Josef y el Fuerte ${ }^{60}$.

Pero el texto del ingeniero queda referido más a establecer una crítica del sistema seguido para la edificación del Fuerte, que a hacer una mera descripción de los elementos existentes. Comenzando con el reducto, éste le parece defectuoso por tres razones: por la figura trapezoidal, no demasiado apta para una defensa integral; por el exceso de altura de sus paramentos, por existir una altura superior en las inmediaciones, que puede llegar a dominar la efectividad defensiva del reducto, y para cuya prevención se propone construir un padrasto, un pequeño fuerte, en esa zona.

En el capítulo sobre la utilidad del Fuerte, verdadera cuestión, para cuya resolución y parecer fue destinado allí Giraldo de Chaves, se insiste, de nuevo, en las consideraciones estratégicas que conocemos desde otros informes parecidos:

Aunque sólo la plaza de Ciudad Rodrigo es la verdadera llabe de Castilla como lo tiene acreditado la experiencia, y combence su posición, no obstante el referido Fuerte aunque situado en un Camino Real que no es el único para entrar en Ciudad Rodrigo, cubre y defiende todo el Campo de Argañán, asegurando dicho País hasta Ciudad Rodrigo, 
es un antemưral de esta Plaza, abrigo de San Felizes, está al frente de una Plaza enemiga y tiene otras ventajas que son obvias reflexionada su situación: por lo que considero indispensable su Guarnición, que es conbenientísima su conserbación y buena defensa ${ }^{61}$.

Sobre el estado de conservación del Fuerte, el texto habla de los reparos necesarios en los revellines y muros exteriores; así como del buen estado en que se encuentran los cuerpos de guardia, interiores y avanzados, horno, pabellones, capilla, plazas de armas y «demás obras accesorias y accidentales». El problema más preocupante para Giraldo de Chaves son las humedades de las bóvedas, para las que prescribe una serie de tratamientos de índole técnica.

Los períodos de abandono del Fuerte debieron ser frecuentes, y durante el tiempo que los mismos duraron se produjeron deterioros que Giraldo de Chaves reseña. Por ejemplo, los que afectaron a los rastrillos de las travesas «que se quitaron por evitar el continuo robo que se experimentaba, pues la poca guarnición que hasta aquí ha existido no ha podido evitarlo, especialmente en los fuertes destacados [revellines]».

De nuevo, en 1753, Moreau se hace cargo de las obras que debemos considerar ya casi como definitivas. Sabemos de la incorporación de Moreau por una nota del Consejo de Guerra en que se lee:

El ingeniero que hizo el tanteo fue D. Pedro Moreau que actualmente tiene la dirección de Castilla, y quien siguió la obra asta que en el año de 1740 se suspendió. Después también ha corrido a su cargo desde el año de 1753 que se bolbió a emprender ${ }^{62}$.

Este mismo ingeniero es quien, en 1759 , hace el balance provisional del costo de los trabajos en el Fuerte, desde su reinicio, treinta años antes, son 6.900.000 reales de vellón los gastados en ese tiempo.

En 1758 es Francisco Codony quien realiza un plano de La Concepción, donde sustancialmente puede apreciarse que el Fuerte tenía en esas fechas la morfología que hoy conocemos. El cuartel de caballería está construido en forma ovoide y consta de dos cuerpos, uno de los cuales, el que se encuentra orientado hacia la frontera con Portugal, no debió llegar a ser enteramente construido, por la situación en que hoy se encuentran sus restos.

En el marco político internacional que configura el Tercer Pacto de Familia, en 1761, la política de Ensenada se dirige en esos años, de nuevo, a reasegurar las débiles fronteras españolas con Portugal $y$, en definitiva, con la potencia inglesa.

El Fuerte de La Concepción debió jugar un papel preponderante en aquellos años, y en los inmediatos, cuando se genera una política 
de beligerancia armada contra Portugal que, iniciada en junio de 1762, concluye, después de episodios como el de la capitulación de Almeida, en el armisticio firmado el 1 de diciembre de 1762, y cuyos mismos términos habían sido ya pactados en el Tratado de Fontainebleau.

La Concepción debió ser la base de partida que utilizó José de Hermosilla, el gran arquitecto de la Ilustración, para su trabajo en la zona, como ingeniero del ejército en campaña levantado por el Conde de Maceda ${ }^{63}$. Hermosilla, que abandona la docencia en la Academia de San Fernando y se reintegra al Cuerpo de Ingenieros militares en $1756^{64}$, al que vuelve, como él mismo escribe, «retribuido al objeto de mi crianza y primeros estudios» ${ }^{65}$, trabaja levantando planos en la Frontera de Castilla, primero en la comarca de Simancoa ${ }^{66}$, y, luego, en 1767 - cinco años después del final de la campaña contra Portugal-, destinado en la misma ribera del Coa, para «formar el plan de los términos y frontera de Castilla».

Sin embargo, los documentos - planos-que presentamos, los únicos de los que, hasta la fecha, tenemos noticia, firmados por José de Hermosilla y referidos a la zona ${ }^{67}$, se encuentran fechados en 1762 y firmados en colaboración con el también ingeniero militar Esteban Peñafiel ${ }^{68}$. El primero de ellos es Plano de la plaza de Almeyda y sus contornos en el que se manifiestan los campamentos e imbestidura de ella con jos puestos que se tomaron ${ }^{69}$, y el segundo es un Plano del castillo de la plaza de Almeyda ${ }^{70}$. De la perfección formal que estos planos ostentan ha escrito D. Rodríguez: «del rigor de su concepto del dibujo, no como apunte sugerente, sino como proceso de definición del espacio arquitectónico, urbanístico o del territorio dan idea los dos dibujos...» ${ }^{71}$.

José de Hermosilla ilustra con su trabajo en las inmediaciones del Fuerte de La Concepción, del que nos venimos ocupando, un último momento en la larga etapa constructiva de este Fuerte y un momento singular en su travesía histórica. Más allá de estas fechas, y hasta 1776, el Fuerte debió ser prácticamente concluido, sobre todo en aquellas de sus defensas exteriores que llevaban paralizadas casi cuarenta años.

Debemos considerar como momento final de este largo proceso, que pone en juego muchos de los recursos ( $\mathrm{y}$, desde luego, muchos también de los mejores técnicos) de la ingeniería militar española, el año de 1776. Un acta conservada en el Archivo de la Catedral de Ciudad Rodrigo da 72 cuenta de la fecha de «inauguración» del Fuerte, con bendición de la Capilla y colocación del Sacramento: treinta de mayo de 1776.

Más allá de esta fecha, y a lo largo de los años que restan hasta los comienzos del siglo XIX, el Fuerte no genera ya ninguna docu- 
mentación de interés, al menos en lo que se refiere a los aspectos constructivos ${ }^{73}$, que aquí nos han irteresado de manera primordial.

La edificación de $L a$ Concepción, por lo demás tremendamente sólida, se aprestaba así, desde esas fechas en las que hemos situado su práctica coronación, a ser uno de los bastiones principales en el sistema de defensa de la Corona española.

Su azarosa historia, a lo largo de la Guerra de la Independencia $\mathrm{y}$, antes, en la conocida como «Guerra de las Naranjas», ilustra la observación realizada por Vicente Mut, el tratadista de arquitectura militar y político del barroco español:

Hacénse estas fortificaciones en las fronteras para defender el costado de los reinos o provincias, impedir la entrada del enemigo, abrigar las fuerzas y armas propias, asegurar la retirada en los buenos progresos de las guerras, acobardar las sublevaciones, amparar los socorros, impedir la diversión de armas por aquella parte y para otras particulares máximas del Estado, que dejo por no ser de este asunto ${ }^{74}$.

La Concepción es, pues, en su historia un emblema del estado ilustrado, empeñado en racionalizar el hecho de sus defensas militares. Su peculiar ubicación al borde mismo de la Frontera o Raya de Castilla hace figurar en la historia a tal fortificación como un «arco» o "puerta», que tanto separa como une dos culturas.

\section{Notas}

1 Este conjunto de medidas militares aquí esbozado se completa y cierra por aquellos años, poniendo en funcionamiento, por ejemplo, nuevos sistemas de reclutamiento, como los que propone Oya y Ozores, miembro del Consejo de Guerra, en su Tratado de levas, quintas y reclutas. Madrid, 1734.

2 Según referencia que consta en Luis Pascual, Cuadernos de reconocimiento de los papeles que existen en Simancas.

3 A lo largo del primer tercio del siglo XVIII se suceden periódicamente las disposiciones del Consejo de Guerra, en orden a poner en defensa la Frontera de Castilla. Las acciones practicadas son, sin embargo, escasas, si exceptuamos el caso de Ciudad Rodrigo, que conoce unas reformas importantes en 1710 , y se refieren, sobre todo, al levantamiento de planos y mapas estratégicos. Es en este sentido remarcable la actividad del gran ingeniero francés Robellin que, en 1722, destinado en la Frontera, levanta los planos de viejas fortificaciones como el castillo de San Felices de los Gallegos, con vistas a futuras obras de restauración. Sobre Robellin, como constructor de la fortaleza de Reims, cf. P. Sica, Historia del urbanismo. Madrid, 1982, pp. 26 ss.

4 Por ejemplo, por A. García Boiza, en «Arquitectura militar en la provincia de Salamanca", Trabajos y días, 13 (1950), pp. 27 -35. 


\section{La ingeniería militar ilustrada y la frontera de Castilla}

5 Las referencias a aspectos constructivos de La Concepción en documentos de Simancas llegan hasta 1764, fecha en la que Julián Giralbo de Chaves remite un pliego de tanteo sobre costes de obras. En lo que se refiere a la documentación existente en el Archivo Histórico Provincial de Salamanca, ésta llega hasta el año 1770, momento en el que se menciona el Fuerte de La Concepción a propósito de una cuestión de abastecimientos para las tropas allí estacionadas (cf. Protocolo notarial de M. A. de Anieto, leg. 5798, fol. 198 r).

6 Todos ellos participan en uno u otro grado en la tarea de la reconstrucción de La Concepción. Para el estudio de los orígenes del Cuerpo de ingenieros militares, cf., A. Cámara Muñoz «La arquitectura militar y los ingenieros de la monarquía española: aspectos de una profesión (1530-1650)». Revista de la Universidad Complutense, 2 (1981), pp. 255-68 y J. A. Maravall, «El régimen de estado moderno y el sistema de fortificación en España", Revista de Estudios Políticos, 18 (1947), pp. 25-33. Los expedientes de la mayoría de los ingenieros que he citado pueden encontrarse en $\mathrm{L}$. Pascual, Indice de Personal de Ingenieros en el XVIII (Ms. en el S.H.M.). Véase, también, H. Capel et alt., Los ingenieros militares en España. Siglo XVIII. Barcelona, 1983.

7 Toda la documentación sobre el asiento de obras del Fuerte de La Concepción en 1735-36 se encuentra en el A.H.P. de Salamanca. Sobre Larra Churriguera y su intervención en la fortificación, vid., M. Teresa Jiménez, "Nuevas aportaciones sobre Manuel de Larra Churriguera", Boletín del Seminario de Arte y Arqueología de Valladolid, 50 y 51 (1975) p. 361, n. 5 y. F. R. de la Flor, «La intervención de Manuel de Larra Churriguera en la reconstrucción del Real Fuerte de La Concepción». Archivo Español de Arte, 224 (1983) pp. 410-16.

8 Sobre esta Escuela véase especialmente J. M. Zapatero, "Síntesis histórica de la fortificación abaluartada", Revista de Historia Militar, 13 (1963), pp. 38-56; La Escuela de Fortificación Hispanoamericana. Sevilla, 1966 y «La Escuela de Fortificación Hispanoamericana", Revista de Historia Militar, 25(1968), pp. 37-52.

9 La problemática de esta reforma ha sido tratada, entre otros, por A. Domínguez Ortiz, Sociedad y estado en el siglo XVIII español. Madrid, 1976, pp. 77 ss.

10 Para el estudio de todo este capítulo de las guerras en esta zona de la antigua Frontera de Castilla, cf. J. Vilhena de Carvalho, Almeida subsidios a sua historia. Viseu, 1973; Villar y Matías, Historia de Salamanca, II, Salamanca, 1887, pp. 478 Ss., y D. D. Horward, Ciudad Rodrigo y Almeida, dos asedios análogos, 1810. Salamanca, 1984.

11 Las referencias a este ingeniero, así como a Bordán, se encuentran extraídas de la colección documental reunida por L. Pascual, Indice del Personal de Ingenieros en el siglo XVIII ( $\mathrm{ms}$. del Servicio Histórico Militar). Véase, también la excelente monografía que a Moreau le ha dedicado M. Manzano Monis, «El Mariscal de Campo D. Pedro Moreau y el Fuerte de La Concepción", Academia, 52 (1981), pp. 201-51.

12 Los planos con los proyectos firmados por Moreau, que se conservan en el Archivo General de Simancas llevan las siguientes signaturas: M. P. y D. XXXI-7, G. M., leg. 3638; M. P. y D. XXXI-8, G. M., leg. 3638; M. P. y D. XXXIII-6 G. M., leg. 3638; M. P. y D. XXXIII-3, G. M., leg. 3638; XXXIII-5, G. M., leg. 3638; M. P. y D. X-90. G. M., leg. 3638.

13 A.G.S.; G.M., Leg. 3638.

14 A.G.S.; G.M., Leg. 3638 .

15 Bordan, aparte de su mención en el escrito de Instrucciones..., no aparece relacionado documentalmente con La Concepción hasta la fecha de 1764, en que es nombrado para gobernar el Fuerte. No llega, sin embargo, a tomar posesión, ya que 
al año siguiente es graduado de ingeniero en jefe. Algunos aspectos de su biografía han sido recogidos por $\mathrm{H}$. Capel et alt., Los ingenieros militares en España. Siglo XVIII. Barcelona, 1983, p. 76.

16 J. Amador Courten, en esa fecha de 1735, se encuentra recién llegado de Venezuela, donde levantó los planos para las obras de San Felipe de Puerto Cabello. Planos suyos, en la zona de la que venimos tratando, son: plano de Fuentes de Oñoro, 1735 (en colaboración con Moreau); plano del Castillo de San Felices (en colaboración con Moreau), 1735; plano de Alba, 1735; plano del Arsenal General de Ciudad Rodrigo, 1737 (en colaboración con Moreau). Para alguno de los detalles de la biografía como ingeniero militar de Courten, cf. H. Capel, Los ingenieros...op.cit., pp. 127-8.

1727 de mayo de 1735. A.G.S.; G.M.; Leg. 3638.

18 A.G.S.; G.M.; Leg. 3638. En este caso he utilizado la copia realizada a finales del siglo pasado por Aparici (Servicio Histórico Militar, sig. 5-5-5-14).

19 Reconocimiento $y$ visita..., fol. $2 \mathrm{r}$.

20 Reconocimiento $y$ visita..., fol. $3 \mathrm{r}$.

21 Este censo no se encuentra entre los papeles del legajo 3638 de Simancas, probablemente se ha sacado del mismo con objeto de incorporarlo a algún catastro posterior.

22 En este punto del documento surge una nueva y concomitante explicación de los motivos que llevan al Cabildo de Ciudad Rodrigo a solicitar la reconstrucción de La Concepción. La baja en la percepción de sus rentas obliga a urgir al poder civil a una acción en su demarcación; acción que tendrá como fin último la restauración de la vida económica. De un modo más preciso, puede decirse que la finca conocida como El Gardón, que es colindante a los terrenos del cerro donde hoy se levanta La Concepción, perteneció hasta el siglo XIX al obispado de Ciudad Rodrigo.

23 Reconocimiento $y$ visita..., fol. $4 \mathrm{r}$.

24 Reconocimiento $y$ visita..., fol. $3 \mathrm{v}$.

25 Reconocimiento y visita..., fol. $3 \mathrm{v}$.

26 Reconocimiento y visita..., fol. $4 \mathrm{r}$.

27 Reconocimiento $y$ visita..., fol. $4 \mathrm{v}$.

28 Entre estas carencias y defectos estructurales, hay que señalar la disposición de los baluartes como uno de los condicionamientos que, heredados de la fase constructiva dirigida por el Duque de Osuna, va a constituir un defecto grave señalado por los ingenieros militares del XVIII en sus informes. En efecto, el ángulo que forma la cortina con el flanco del baluarte es de 90 grados, mientras que ya a comienzos del siglo XVIII, y recogido antes en el "primer sistema de fortificación" de Vauban, aparece una abertura de ángulo de hasta 100 grados, o, en todo caso, se opera en el baluarte la modificación conocida como orejón, que viene completada por las tenazas, ya en el foso.

29 Algunas escasas noticias sobre este recinto abaluartado pueden recogerse en G. Toribio de Dios, Historia de la villa de San Felices de los Gallegos. Valladolid, $1940,64$.

30 Cf. H. Capel et alt., Los ingenieros..., op. cit., p. 402.

31 Reconocimiento $y$ visita..., fol. $7 \mathrm{r}$.

32 El paso de Antonio Jordán por el Cuerpo de Ingenieros se encuentra detallado en el libro de H. Capel, Los ingenieros...op.cit., p. 240. Sin embargo, la presencia de Jordán en La Concepción no se encuentra confirmada con posterioridad en ninguno de los documentos que he consultado. 


\section{La ingeniería militar ilustrada y la frontera de Castilla}

33 A.G.S. G.M., Leg. 3638. El diseño de Bordick supone un llamativo avance sobre otras plantas pentagonales coetáneas a la que él presenta, por ejemplo, a la del propio Fernández de Medrano, respecto de la cual presenta una innovación en los baluartes, los llamados orejones, que pone en uso en toda Europa el sistema Vauban.

34 A.G.S.; G.M., Leg. 3638.

35 A.G.S.; G.M., Leg. 3638.

36 Gabriel Puig es otro eslabón más, junto a Calabro, La Ferriere, Giraldo de Chaves..., que vincula las obras de fortificación de Aldea del Obispo con la Academia de Matemáticas de Barcelona. En concreto, G. Puig aparece trabajando en las obras de la ciudadela de Barcelona. Vid. infra: «Un manuscrito inédito...»

37 Carta de 3 de noviembre de 1735. A.G.S.; G.M., Leg. 3638.

38 A.G.S.; G.M., Leg. 3638.

39 El Pliego de Condiciones se encuentra en el Protocolo notarial de Manuel Antonio le Anieto, de 1736 (A.H.P., S. A., 5797). La extensión misma del documento me ha forzado a hacer recortes sustanciales en su texto, salvaguardando aquellas zonas que presentan un mayor interés desde el punto de vista de la ingeniería. El léxico técnico empleado por Pedro Moreau en estas Condiciones es muy sencillo y no he creído oportuno hacer notas en él. Por lo demás, he respetado el sistema ortográfico que presenta el documento.

40 Se conservan también de estas mismas fechas unos interesantes proyectos del ingeniero para cuarteles de caballería en Arévalo, Avila, Campo de Gibraltar... Vid. M. C. Alvarez Terán, Mapas, planos y dibujos, catálogo. XXIX/1, Valladolid, 1980.

41 Libro de Bautismos de la Parroquia de Aldea del Obispo. Años 1763 a 1807, tomo $3 .^{\circ}$, fols, 306-308.

42 Véase su Carta al duque de Montemar (24 de agosto de 1737), sobre los cambios en las bóvedas a realizar según el proyecto de Moreau. $\mathrm{H}$. Capel, que ha estudiado la trayectoria profesional de este ingeniero, no lo relaciona, sin embargo, con La Concepción (Cf. Los ingenieros... op. cit., pp. 244-247). La Ferriere tiene una intervención destacada en el programa borbónico para la arquitectura militar marítima del reino de Galicia; véanse referencias a su obra en Rodríguez Villasante, Las defensas de Galicia. La Coruña, 1985, pp. 100 y ss., y en J. R. Soraluce, Castillos y fortificaciones de Galicia. La Coruña, 1985.

43 J. R. Soraluce, Castillos y...op.cit., p. 24.

44 V. Tovar Martín, "Algunas noticias sobre el arquitecto Manuel de Larra Churriguera", Archivo Español de Arte, (1972), pp. 271-285 y, siguiendo a esta investigadora, M. Teresa Jiménez, "Nuevas aportaciones sobre Manuel de Larra Churriguera", Boletín del Seminario de Arte y Arqueología de Valladolid, 50-1 (1975), pp. 343-367, situaban la presencia de Larra Churriguera en las obras del Fuerte de La Concepción en el año 1724, debido a una mala lectura de documentos, ya que en este año no había comenzado todavía la restauración. Por otra parte el testamento de José de Larra, padre de Larra Churriguera, conservado en el A. H. P. de Salamanca (sig. 3430, fol. 662v y ss.), está claramente fechado en 1738, y no en 1724, como aseguran estas investigadoras.

Manuel de Larra Churriguera participa en otras obras arquitectónicas en la zona. Se trata de la reforma de la iglesia de La Alberca y en la fábrica de las Descalzas de Ciudad Rodrigo. cf. M. F. Díaz Tordesillas, La Biblioteca Universitaria de Salamanca y sus verdaderos artífices. Salamanca, 1969, y, sobre todo, A. Rodríguez G. de Ceballos, Los Churriguera. Madrid, 1971.

45 A. H. P. de Salamanca, Protocolo notarial de Manuel Antonio de Anieto, año 1736, sig. 5797. Los documentos que hacen referencia a la intervención de Larra 
Churriguera se encuentran entre los Autos hechos con motivo del pliego dado en beneficio de las obras y operarios del Real Fuerte de La Concepción por don Manuel de Larra Churriguera, Maestro Arquitecto, y allanamientos hechos por éste al pliego de reparos puesto por el señor Intendente (fols. $387 \mathrm{r}$ al $418 \mathrm{v}$ ).

46 El plano lleva la signatura del A. H. N.: M. P. y D. XLVII-46 e iba acompañado de la carta que reproduzco infra (A. H. N., G. M., leg. 3638); el alzado lleva la sig. del A.H. N.: M. P. y D. XLVII-47.

47 A. H. P. de Salamanca, Protocolo notarial de Manuel Antonio de Anieto, sig. 5797, fol, 401r.

48 Los planos del Fuerte de La Concepción en estas fechas tienen las siguientes signaturas en el A. H. N.: M. P. y D. XXXIII-3; XIXIXIIl-4; XXXIII-5; XXXIII-6; XXXI-7; XXXI-8; XXXIX-74; XLVII-46; XLVII-47; X-90.

49 Carta de Manuel de Larra Churriguera al Duque de Montemar, 19 de enero de 1739. A. G. S.; G. M., Leg. 3638. Más allá de esta obra concreta y de estas fechas, Larra Churriguera continúa como maestro de obras del Fuerte, y como tal aparece relacionado en un acta capitular de la Catedral de Ciudad Rodrigo, año 1741.

$50 \mathrm{Su}$ primer documento enviado desde la zona es una relación estimativa de los gastos necesarios para acabar las obras del Fuerte.

51 Véase mi artículo «La intervención de Larra Churriguera en el Fuerte de La Concepción", Archivo español de Arte, 224 (1983), pp. 400-16. Vengo aquí, en consecuencia, a precisar algunas de las atribuciones que hice en dicho artículo. En definitiva, la base de la decoración de la fachada del Fuerte pertenece a Pedro Moreau; Larra Churriguera la realiza y planea también toda la ingeniosa estructura interna. Finalmente, La Ferriere se replantea el tema de la fachada posterior que da al patio de armas, y sitúa allí la casa del Gobernador, que en un principio y conforme al propósito de Moreau reflejado en sus plantas, iba a quedar ubicada en el centro de la plaza de armas.

52 Algunos historiadores del arte se han empeñado, también, en hacer todavía más enrevesados algunos aspectos constructivos de La Concepción. Por ejemplo, don Rafael Laínez Alcalá que, en un informe que remite a la alcaldía de Aldea del Obispo en el año 1967, afirma que el escudo de la fachada es de Alberto Churriguera, sin otros datos ni documentos que avalen su referencia.

53 No conozco ningún estudio monográfico sobre la Junta Real de Fortificaciones, algunas referencias a la misma pueden encontrarse en C. Espejo, «Enumeración y atribuciones de algunas Juntas de la Administración española desde el siglo XVI hasta el año 1800", Revista de las Bibliotecas, Archivos y Museos, 32 (1931), pp. 325-62. Para un estudio general de las Juntas, pero sin alusión concreta a la de Fortificación, cf., J. L. Bermejo, "Notas sobre Juntas del Antiguo Régimen", Actas del IV Symposium de Historia de la Administración. Madrid, 1983, pp. 93-108.

5423 de julio de 1751. A.G.S., G.M.; Leg. 3638. Sobre este ingeniero cf. H. Capel, Ingenieros...op.cit., p. 200.

55 A.G.S.; G.M.; Leg. 3638.

56 Carta escrita al Marqués de la Ensenada desde el Fuerte de la Concepción. A.G.S.; G.M. Leg. 3638 .

57 H. Capel, Ingenieros..., p. 211.

58 Sig .3 2-4-5.

59 Lo que no coincidiría tampoco con la fecha de 1765 que da $\mathrm{H}$. Capel para la realización del plano del Fuerte (Ingenieros.... op.cit., p.211). En el Servicio Histórico Militar el informe de Giraldo de Chaves aparece relacionado como perteneciente al año 1796. 


\section{La ingeniería militar ilustrada y la frontera de Castilla}

60 S.H.M.; Leg. 3-2-4-5, Fol. 1 v.

61 Reconocimiento del Fuerte..., S.H.M.: Leg. 3-2-4-5, Fol. 2 r.

62 A.G.S.; G.M.; Leg. 3638.

63 El trabajo de José de Hermosilla como ingeniero militar en la Frontera de Castilla se encuentra conectado con su intervención en algunas obras de carácter civil realizadas en Salamanca, tales como la restauración del Palacio de Anaya. De todo ello da cuenta Llaguno, Noticias de los arquitectos y arquitectura de España desde su restauración, IV. Madrid, 1829, pp. 264-266. Véase, también, C. Sambricio, «José de Hermosilla y el ideal historicista en la arquitectura de la Ilustración», Goya, 151(1980), pp. 140-151.

64 Reintegración que se produce como consecuencia de las desavenencias con Sachetti y después de su expulsión de las obras del Palacio Real.

65 Algunas referencias al trabajo de José de Hermosilla como ingeniero militar pueden encontrarse en la reciente publicación de D. Rodríguez Ruiz, "De la utopía a la Academia: el tratado de arquitectura civil de José de Hermosilla", Fragmentos, 3 (1984), pp. 58-80.

66 Cf. H. Capel, Los ingenieros...op.cit., pp. 226-7. En 1763, Hermosilla, en calidad de ingeniero extraordinario participó bajo las órdenes de Antonio Gaver en la confección del plano topográfico de esa Comarca.

67 Existen otros planos que recogen diversas perspectivas sobre la ribera del Coa y, en concreto, sobre la plaza fuerte de Almeida; estando realizados por ingenieros militares españoles (alguno de ellos, podría ser Cermeño, el proyectista de gran parte de la fortificación de Ciudad Rodrigo). Los publica J. Vilhena de Carvalho en su Almeida. Subsidios para a sua historia. Viseu, 1973, pp. 161 у 163.

68 Los dos planos figuran en el Catálogo de E. Santiago, La historia en los mapas manuscritos de la Biblioteca nacional. Madrid, 1984, con los números 411 y 413.

69 Biblioteca Nacional. Ms. 73 (sección de Geografía y Mapas).

70 Biblioteca Nacional. Ms. 68 (sección de Geografía y Mapas).

71 D. Rodríguez, «De la utopía a la...» op.cit., p. 79; n. 103.

72 Fuerte de La Concepción. Libro de Bautismos, desde 1763 a 1807; fol. 7 y ss.

73 La fecha del último documento del siglo XVIII que, referido a La Concepción, hemos podido encontrar, es la del 6 de mayo de 1797:

«Revista pasada por mi, D. Carlos Rusconi, Comisario de Guerra de los Reales Exércitos al segundo batallón del regimiento de Infantería de Zamora del que es Coronel el Brigadier Conde del Vado en el Real Fuerte de la Concepción a seis de mayo de mil setecientos noventa y siete, y ha de servir para el axuste del bayer que le corresponde en dicho mes".

(Guardas del legajo VI - proceso de 1584 entre Guadalmiro y el Convento de San Jerónimo Archivo Diocesano de Salamanca).

No he podido comprobar documentalmente algunas referencias que he recibido sobre la importancia que alcanza, en el siglo XVIII, la farmacia del Fuerte de La Concepción. Esta y otras cuestiones marginales deberán ser tratadas de una manera monográfica más adelante, y, en este sentido, mi estudio pretende sólo servir de apoyatura a nuevos trabajos que delimiten la importancia que, en todos los órdenes, tuvo este establecimiento militar.

74 Arquitectura Militar. Mallorca, 1664, p. 72. 